\title{
Measurements and modelling of atmospheric pollution over the Paris area: an overview of the ESQUIF Project
}

\author{
L. Menut ${ }^{1, *}$, R. Vautard ${ }^{1}$, C. Flamant ${ }^{2}$, C. Abonnel $^{7}$, M. Beekmann ${ }^{2}$, P. Chazette ${ }^{4}$, P. H. Flamant ${ }^{1}$, \\ D. Gombert ${ }^{6}$, D. Guédalia ${ }^{5}$, D. Kley ${ }^{8}$, M. P. Lefebvre ${ }^{7}$, B. Lossec ${ }^{7}$, D. Martin ${ }^{4}$, G. Mégie ${ }^{2}$, \\ P. Perros ${ }^{3}$, M. Sicard ${ }^{2}$, G. Toupance ${ }^{3}$ \\ ${ }^{1}$ Laboratoire de Météorologie Dynamique, CNRS, France \\ ${ }^{2}$ Service d'Aéronomie, CNRS, France \\ ${ }^{3}$ Laboratoire Interuniversitaire des Systèmes Atmosphériques, CNRS, France \\ ${ }^{4}$ Laboratoire des Sciences du Climat et de l'Environnement, Commissariat à l'Energie Atomique, CNRS, France \\ ${ }^{5}$ Laboratoire d'Aérologie, CNRS-Université Paul Sabatier, France \\ ${ }^{6}$ AIRPARIF, Paris, France \\ ${ }^{7}$ MÉTÉO-FRANCE, Paris, France \\ ${ }^{8}$ Forschungszentrum Jülich, D-52425 Jülich, Germany
}

Received: 3 April 2000 / Revised: 28 June 2000 / Accepted: 4 July 2000

\begin{abstract}
The "Étude et Simulation de la QUalité de l'air en Ile de France" (ESQUIF) project is the first integrated project dedicated to the study of the processes leading to air pollution events over the Paris area. The project was carried out over two years (summer 1998 to winter 2000) to document all types of meteorological conditions favourable to air quality degradation, and in particular to photo oxydant formation. The goals of ESQUIF are (1) to improve our understanding of the relevant chemical and dynamical processes and, in turn, improve their parametrizations in numerical models, and (2) to improve and validate existing models dedicated to pollution analysis, scenarios and/or forecasting, by establishing a comprehensive and thorough database. We present the rationale of the ESQUIF project and we describe the experimental set-up. We also report on the first experiments which took place during the summer of 1998 involving surface networks, and remote sensing instruments as well as several aircraft. Focusing on three days of August 1998, the relative contributions of longrange transported and locally-produced ozone to the elevated ozone concentrations observed during this period are discussed and chemistry-transport model preliminary results on this period are compared to measurements.
\end{abstract}

Key words: Atmospheric composition and structure (pollution - urban and regional; troposphere composition and chemistry) - Meteorology and atmospheric dynamics (mesoscale meteorology)

\footnotetext{
*Present address:

Laboratoire de Météorologie Dynamique, Institut P.S. Laplace, Ecole Polytechnique, 91128 Palaiseau Cedex, France

Correspondence to: L. Menut

e-mail: menut@lmd.polytechnique.fr
}

\section{Rationale and objectives of the ESQUIF project}

As in many big cities throughout the world, pollution levels in the Paris area due to concentrated activity have become a major health issue. Current predictive capabilities must be improved to enable policy makers to reach balanced decisions on emission reduction strategies. This requires a thorough understanding of the processes and factors affecting the formation of pollutants and their concentrations.

Air quality over Paris is continuously surveyed by a dedicated surface network carrying out measurements of critical pollutant concentrations (AIRPARIF). However, surface measurements are not sufficient to fully understand the pollutants dynamics and chemistry. Also, unlike cities such as Los Angeles (McElroy and Smith, 1993), Athens (Ziomas, 1998), Mexico City (Doran et al., 1998) where the local dynamical processes are dominant due to mountain barriers, and land-sea breeze regimes, the Paris agglomeration has a rather flat topography and is thus also strongly influenced by synoptic and local-scale meteorological conditions. Moreover, photochemical pollution in this area is actually both due to photooxydant build-up from local emissions and to large-scale transport of ozone (as studied over Boston during the North Atlantic Regional Experiment) formed over other areas of Europe. The determination of their respective role, as well as several other scientific issues, requires a specific research project where numerical modelling and measurement campaigns are simultaneously performed. During the last decade, several campaigns have been carried out to study photochemical pollution at the regional scale. POLLUMET (Pollution and Meteorology) was carried out in Switzerland (19921994) and illustrated the influence of the Milan ozone plume (Prévôt et al., 1997). BERLIOZ (Berlin Ozone) 
(Volz-Thomas et al., 2000; Rappenglueck et al., 2000) was designed to study the chemical reactions taking place in the plume of the city of Berlin (1998). LOOPPIPAPO (Limitation of oxidants production) focused on chemical regimes in the Po valley, over Milan (Neftel, 1999).

ESQUIF ("Étude et Simulation de la QUalité de l'air en Ile de France", a French acronym for "Air quality study and modelling over the Paris area") is such a research initiative. It is the first important project dedicated to the study of pollution in this area. The particular interest of the Paris area stems from its geographical situation: it is a large city located distant from other populated areas, by about $200 \mathrm{~km}$. It is therefore in principle easier than for other European cities to distinguish the air masses charged with locally emitted pollutants from those charged with pollutants emitted in remote areas. This should allow one to distinguish between errors deriving from boundary conditions and from model parametrizations in regional model simulations. Another geographical interest of the Paris area is its low topography, which in the absence of local forcing makes the modelling of the accumulation/ dispersion of pollutants more complex (Lossec, 1992; Dupont et al., 1999). More specifically, the ESQUIF project focuses on several research issues, the most important ones listed here as:

1. The thermodynamics of the boundary layer in and around a big city: the main questions are (a) the role of the vertical structure of the boundary layer and the turbulent mixing processes during pollution episodes, and (b) whether models are able to simulate the air flow, its vertical structure and the surface fluxes encountered during low dispersion episodes, and, if not, how to improve the various parametrizations used within the models.

2. The photochemistry of pollutants: the focus here is essentially on processes modifying the radiative fluxes and thereby photolysis rates (clouds, aerosols, total ozone column).
3. The transport of pollutants at the interface of the urban/regional and the continental scale: we will evaluate the concentration of ozone and its precursors both at the inflow boundaries of the domain and in the city plume.

4. The physical and chemical evolution of urban and suburban aerosols and their representation in air quality chemistry-transport models.

These research issues aim to give some answers for the following environmental issues: (1) the origin of ozone episodes in the Paris area, including the determination of the relative role of local emissions and large-scale transport, (2) the influence of the city area on neighbouring regions, including the study of the pollutants in the plume, their aging and the horizontal and vertical extent of this plume; (3) the determination of the photochemical regimes $\left(\mathrm{NO}_{x}\right.$ or VOC limited) and their spatial distribution, and (4) the evaluation of existing emission inventories using measurements acquired during the campaign.

The project has been initiated jointly by the Institut Pierre Simon Laplace (IPSL) and the Laboratoire Interuniversitaire des Systèmes Atmosphériques (LISA), and the partnership is extended to the Laboratoire d'Aérologie, the Forschung Zentrum of Jülich, AIRPARIF (the local air-quality monitoring network) and MétéoFrance (see Table 1). The project extended over two years (July 1998-January 2000).

The measurement campaign started during the summer of 1998, and endic during the winter of 1999-2000. Ten episodes of 1-5 days were documented, denoted hereafter the ESQUIF IOPs, (intensive observation periods). These IOP days were selected on the basis of weather forecasts favourable to degradation of air quality. Table 2 lists the main characteristics of the meteorological situations encountered during these IOPs.

Following the ESQUIF objectives, the campaign included aircraft and ground-based measurements. Various flight plans were defined: flights to document

Table 1. List of institutes and people involved in the ESQUIF experiment

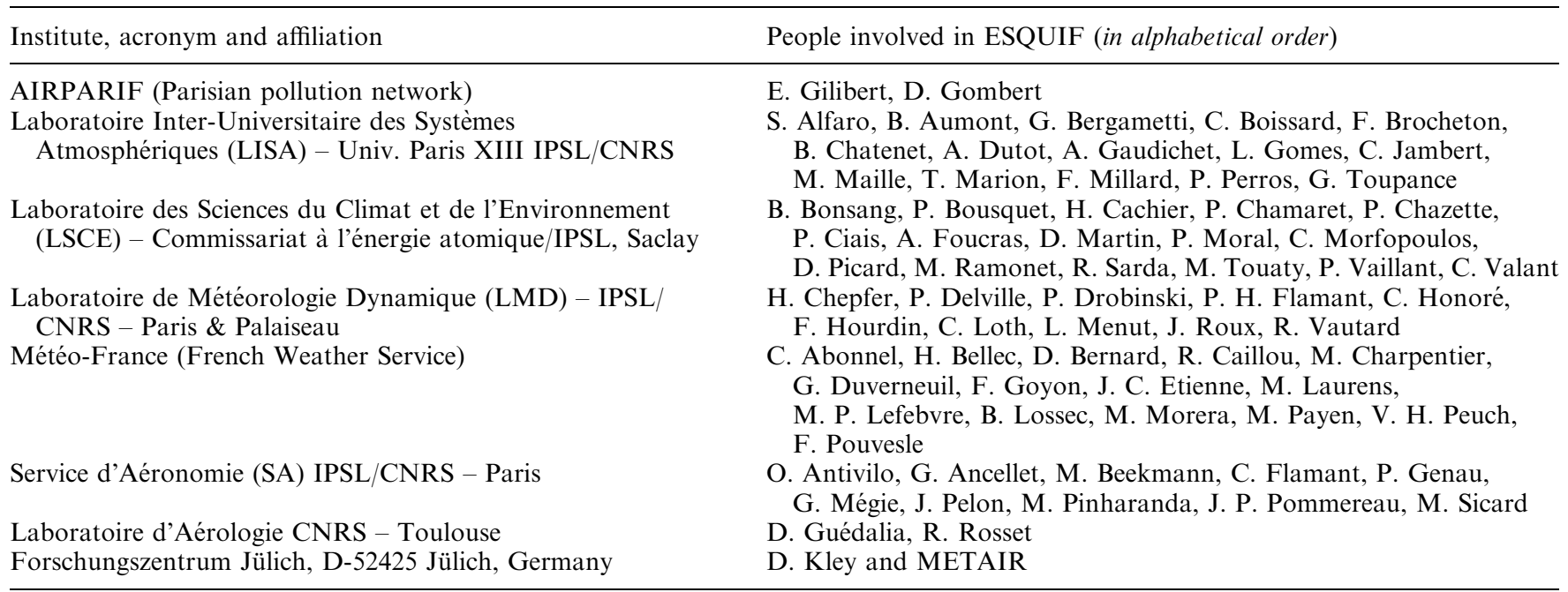


spatial ozone distribution in loops around the city at various distances from the centre, the "city plume" flights to follow the urban plume, the "chemical regimes" flights occurring at constant latitude over the Paris area, and the "regular" flights performed to obtain a climatology of long-lived trace gas species around the Paris area.

The study is organized as follows: in Sect. 2, we present the main defined experiments and the experimental strategy designed to address the scientific goals in the framework of ESQUIF. The instrumental set-up is also briefly discussed. In Sect. 3, the models to be used in the framework of ESQUIF are briefly described. Section 4 is devoted to the description of the meteorological conditions and experimental set-up during the two IOPs performed during the summer of 1998 and to report on results obtained during the second IOP. Chemistry-transport model results are presented and compared to measurements in Sect. 5. In Sect. 6 we discuss the perspectives of further work within the ESQUIF project.

Table 2. Overview of the ten IOPs of ESQUIF from 1998 to 2000. The 'airmass' is specified in order to check its continental or maritime origin (with 'st.' for stagnation). $\mathrm{T}_{\text {surf }}$ and $\mathrm{O}_{3}$ correspond to maximal surface temperature and ozone concentrations, respectively, observed over the Paris city during the diurnal day. Some additional remarks are displayed on the mean meteorological conditions observed over each whole IOP

\begin{tabular}{|c|c|c|c|}
\hline IOP & Dates & Airmass & $\begin{array}{l}\text { Remarks } \\
\text { (whole IOP) }\end{array}$ \\
\hline \multirow[t]{2}{*}{1} & $25 / 07 / 1998$ & Continental & \multirow{2}{*}{$\begin{array}{l}\text { Mostly cloudy by } \\
\text { medium and high cloud } \\
\text { no wind }\end{array}$} \\
\hline & $26 / 07 / 1998$ & $\begin{array}{l}1-2 \text { days st. } \\
\text { stagnation }\end{array}$ & \\
\hline \multirow[t]{7}{*}{2} & $6 / 08 / 1998$ & Continental & Clear sky \\
\hline & $7 / 08 / 1998$ & 2-4 days st. & Hot temperature \\
\hline & $8 / 08 / 1998$ & & Light winds \\
\hline & $9 / 08 / 1998$ & & \\
\hline & $10 / 08 / 1998$ & & \\
\hline & $11 / 08 / 1998$ & & \\
\hline & $12 / 08 / 1998$ & & \\
\hline \multirow[t]{2}{*}{3} & $16 / 06 / 1999$ & Continental & Overcast after 12 UT. \\
\hline & $17 / 06 / 1999$ & 3-4 days st. & Wind $(\mathrm{NE})<3 \mathrm{~m} / \mathrm{s}$ \\
\hline \multirow[t]{2}{*}{4} & $25 / 06 / 1999$ & Continental & Clear sky \\
\hline & $26 / 06 / 1999$ & 3-4 days st. & Wind $(E) \approx 5 \mathrm{~m} / \mathrm{s}$ \\
\hline \multirow[t]{2}{*}{5} & $1 / 07 / 1999$ & Maritime & Clear sky \\
\hline & $2 / 07 / 1999$ & & Wind $(\mathrm{SE}) \approx 4 \mathrm{~m} / \mathrm{s}$ \\
\hline \multirow[t]{3}{*}{6} & $16 / 07 / 1999$ & Maritime & \multirow[t]{3}{*}{ Clear sky } \\
\hline & $17 / 07 / 1999$ & then stagnant & \\
\hline & 18/07/1999 & & \\
\hline \multirow[t]{2}{*}{7} & $24 / 07 / 1999$ & Continental & \multirow{2}{*}{$\begin{array}{l}\text { Paris plume tracking } \\
\text { in Brittany. Windy }\end{array}$} \\
\hline & $25 / 07 / 1999$ & 2-3 days st. & \\
\hline \multirow[t]{4}{*}{8} & $28 / 07 / 1999$ & Continental & \multirow[t]{4}{*}{ Light wind $<2 \mathrm{~m} / \mathrm{s}$} \\
\hline & $29 / 07 / 1999$ & 3-4 days st. & \\
\hline & $30 / 07 / 1999$ & & \\
\hline & $31 / 07 / 1999$ & & \\
\hline \multirow[t]{2}{*}{9} & $07 / 10 / 1999$ & Continental & \multirow{5}{*}{$\begin{array}{l}\text { Anticyclonic situation } \\
\mathrm{NO} \rightarrow \mathrm{NO}_{2} \text { experiment } \\
\text { High } \mathrm{NO}_{z} \text { concentrations } \\
\text { Plume to west of Paris }\end{array}$} \\
\hline & $08 / 10 / 1999$ & 2-3 days st. & \\
\hline \multirow[t]{3}{*}{10} & $26 / 01 / 2000$ & Continental & \\
\hline & $27 / 01 / 2000$ & & \\
\hline & $28 / 01 / 2000$ & & \\
\hline
\end{tabular}

\section{Overview of the experimental strategy and set-up}

\subsection{IOP organization and forecast}

In order to trigger IOPs, several models and model outputs were used (see description later). First, we used weather forecasts issued at Météo-France and compared them to the European Centre for Medium-Range Weather Forecasts (ECMWF) and National Centers for Environmental Prediction (NCEP) forecasts. When favourable weather conditions were forecast and when the forecast became stable (typically $2-3$ days before the experiment), we checked the chemistry-transport forecast model CHIMERE (Menut et al., 2000). This model is forced either by ECMWF or Météo-France meteorological variables (wind, temperature, humidity, cloudiness) and forecasts pollutant fields (ozone in particular) which were used to trigger an IOP. A particular emphasis was put on the nature of the episode (localscale or large-scale). The availability of airplanes and instruments was also taken into account in the design of the experiment (a complete list of instruments is displayed in the Table 3). Finally, the IOPs were chosen to be meteorologically as different as possible in order to collect a large range of situations (e.g. continental air, maritime air, hot weather, stagnation conditions).

\subsection{Aircraft measurements}

Five aircraft (two Piper AZTECs, a MERLIN IV, the Fokker 27 "ARAT" and a DIMONA) were used to loop around Paris at various distances and to collect measurements of $\mathrm{CO}, \mathrm{NO}, \mathrm{NO}_{2}, \mathrm{O}_{3}$ and NMVOCs (non-methane volatile organic compounds) as well as standard meteorological parameters. The flight plans may be defined as (1) 'local and regional' flights (Fig. 1), (2) 'meso-scale' flights (Fig. 2), (3) 'dedicated' flights (urban plume and chemical regimes) and (4) the 'regular' flights, devoted to the $\mathrm{CO}_{2}$ climatology, as follows:

2.2.1 The 'local and regional' flights. In order to study the local and regional pollutants concentrations around the Paris agglomeration, three majors flight patterns were designed as loops around the city (Fig. 1):

a. 'Urban' flights, made above the Paris "ring" (limit of the Paris city) at 500, 1000 and $1500 \mathrm{~m} \mathrm{AGL}$, aim at characterizing pollutant concentration above the main sources (traffic, industry).

b. 'Suburban' flights, made at a distance of $20 \mathrm{~km}$ from the centre of Paris, were designed to document the chemical compounds concentrations at the border of the urban area. In addition, these flights will also be used for determining the gradient of concentrations between upwind and downwind the city, in order to help evaluating emission inventories.

c. The 'Ile de France' flights (known as 'IdF' flights), made at a distance of $50 \mathrm{~km}$ from the centre of Paris, 
Table 3. Description of the ground measurements deployed during the ESQUIF experiments

\begin{tabular}{|c|c|c|c|}
\hline Measurements & Instruments & Site & Measurements \\
\hline \multirow[t]{5}{*}{ Dynamics } & Lidar & Palaiseau & ABL depth, entrainment zone depth \\
\hline & Soundings & Trappes & $P_{z}, T_{z}, R H_{z}, U_{z}, V_{z}, q_{z}$ \\
\hline & Surface network & $\mathrm{IdF}$ & $P_{2 \mathrm{~m}}, T_{2 \mathrm{~m}}, R H_{2 \mathrm{~m}}, U_{10 \mathrm{~m}} V_{10 \mathrm{~m}}$ \\
\hline & Sensors ${ }^{\mathrm{a}}$ & Paris, Saclay & $T_{2 \mathrm{~m}}, \mathrm{RH}_{2 \mathrm{~m}}$ \\
\hline & Station & Créteil & $T_{20 \mathrm{~m}}, R H_{20 \mathrm{~m}}, u_{20 \mathrm{~m}}, v_{20 \mathrm{~m}}$ \\
\hline \multirow{11}{*}{ Aerosol } & Lidar & Palaiseau & Aerosol optical depth, extinction coefficient \\
\hline & Lidar & Paris & Aerosol optical depth, extinction coefficient \\
\hline & Nephelometer $^{\mathrm{a}}$ & Paris, Saclay & Aerosol scattering coefficient \\
\hline & Aethalometer $^{\mathrm{a}}$ & Paris, Saclay & Surface black carbon concentration \\
\hline & Aerosol sampling line ${ }^{a}$ & Paris, Saclay & Chemical apportionment \\
\hline & Particule counter $^{\mathrm{a}}$ & Paris, Saclay & Aerosol size distribution $(\oslash: 0 \rightarrow 3 \mu \mathrm{m})$ \\
\hline & Diffusion battery $^{\mathrm{a}}$ & Paris, Saclay & Aerosol size distribution $(\oslash: 7 \mathrm{~nm} \rightarrow 0.2 \mu \mathrm{m})$ \\
\hline & TEOM balance ${ }^{\mathrm{a}}$ & Paris, Saclay & PM1 or PM10 aerosol mass concentration \\
\hline & $\mathrm{J}\left(\mathrm{NO}_{2}\right)$ & Paris & $\mathrm{NO}_{2}$ photolysis frequencies \\
\hline & TEOM balance & Créteil & PM1 or PM10 aerosol mass concentration \\
\hline & Cascad impactor & Créteil & Aerosol mass size distribution $(0.03$ to $10 \mu \mathrm{m})$ \\
\hline \multirow{5}{*}{ Chemistry } & SANOA & Paris & $\mathrm{O}_{3}, \mathrm{NO}_{2}, \mathrm{NO}, \mathrm{SO}_{2}$, VOC's \\
\hline & SAOZ & Verrieres & $\mathrm{O}_{3}$ \\
\hline & Surface network & $\mathrm{IdF}$ & $\mathrm{O}_{3}, \mathrm{NO}_{2}, \mathrm{NO}, \mathrm{SO}_{2}, \mathrm{CO}, \mathrm{PM}_{10}$ \\
\hline & Photometers & $\begin{array}{l}\text { Paris, Palaiseau } \\
\text { Saclay, Créteil }\end{array}$ & $\begin{array}{l}\text { Optical thickness, Angström exponent } \\
\text { size distribution }\end{array}$ \\
\hline & Analyzers ${ }^{\mathrm{b}}$ & Créteil & $\mathrm{O}_{3}, \mathrm{NO}_{2}, \mathrm{NO}, \mathrm{PAN}, \mathrm{NMVOC}$ 's \\
\hline
\end{tabular}

$P, T, R H, U, V, q$ and $z$ designate pressure, temperature, relative humidity, zonal and meridien components of the wind, specific humidity and altitude, respectively. $\mathrm{O}_{3}, \mathrm{CO}$, etc... refer to concentrations for ozone, carbon monoxide, etc.

${ }^{\mathrm{a}}$ Indicates instruments in LSCE mobile aerosol station CMAS

b Indicates instruments in LISA 'MILEAGE' stations were also designed to explore the vertical distribution of pollutants by means of soundings at four points in each direction from the city, and to characterize pollution at rural sites close to the city.

2.2.2 The 'meso-scale' flights. The 'meso-scale' flights ('Meso' flights) were designed to document pollutant concentration fields (ozone, in particular) at a distance of $150 \mathrm{~km}$ from the centre of Paris (Fig. 2). These flights were performed with the MERLIN aircraft (Table 4) and the flights were made between once and twice per IOP (depending on the meteorological situation). These 'Meso' flights, along with the 'IdF' flights, are to be used to provide boundary counditions for regional air quality models, and to understand the transport of pollutants at the regional scale.

2.2.3 The 'dedicated' flights. The 'dedicated' flights were designed to provide a database on the whole Paris area $(130 \times 120 \mathrm{~km})$. These data include ozone, nitrogen compounds (NO, $\mathrm{NO}_{2}, \mathrm{NO}_{y}, \mathrm{HNO}_{3}, \mathrm{PAN}$ ) and NMHCs $\left(\mathrm{C}_{2}-\mathrm{C}_{4}\right)$ measured by the ARAT aircraft (Table 4 ) in the boundary layer using a regular trajectory (5 legs of $130 \mathrm{~km}$ separated by $30 \mathrm{~km}$ ). The aim of the chemical regimes experiment is to build a map of the area surrounding Paris with respect to the $\mathrm{NO}_{x}$ and VOC sensitivity regimes under meteorological situations typical of high pollutant levels. This is done using indicator species (Milford et al., 1994; Sillman, 1995) such as $\mathrm{O}_{3} / \mathrm{NO}_{y}, \mathrm{O}_{3} / \mathrm{NO}_{z}$ and $\mathrm{O}_{3} / \mathrm{HNO}_{3}$. Some other ARAT flights were designed to study the urban plume: perpendicular flight legs to the mean wind direction were performed and gave pollutants gradients in and around the city plume.

In the same manner, chemical regimes will be studied using the DIMONA flights (Lehning et al., 1998). The DIMONA aircraft (see Table 4 for measurements) circumnavigated the city of Paris, well inside the mixing layer, at a distance of about $30 \mathrm{~km}$ from the city centre. Designed according to a trifold strategy, the first objective was to obtain measurements of the $\mathrm{VOC} /$ $\mathrm{NO}_{x}$ concentration ratios at a point close in time to the emissions. A short extrapolation to zero time will be made using the concept of chemical age [where the chemical age, $\mathrm{CA}$, is the time integrated $\mathrm{OH}$ concentration from emission to the time of measurement, according to $\ln \left(\mathrm{NO}_{y}\right) /\left(\mathrm{NO}_{x}\right)=\mathrm{k}(\mathrm{OH}) \mathrm{dt}=\mathrm{k} \mathrm{CA}$, where $\mathrm{k}$ is the rate coefficient of oxidation of $\mathrm{NO}_{2}$ to $\mathrm{HNO}_{3}$.]. Here, the fact is used that emissions of the oxides of nitrogen are to a large extent in the form of NO. Photochemical equilibrium between $\mathrm{NO}$ and $\mathrm{NO}_{2}$ is rapidly established within 1-2 min and the consecutive oxidation of $\mathrm{NO}_{2}$ to $\mathrm{HNO}_{3}$ by $\mathrm{OH}$ occurs with a known rate coefficient. Then $\mathrm{CA}$ can be derived from the measured ratio of $\mathrm{NO}_{y}$ to $\mathrm{NO}_{x}$ concentrations. The second objective was to experimentally determine integrated $\mathrm{NO}_{x}$ and VOC emission rates over the Paris area. This can be done, once the chemical age has been determined, from quasi-continuous $\mathrm{NO}_{x}$ and VOC measurements along the circumferential flight track. As an additional parameter the mixing layer height must be known. The third objective centered around the 

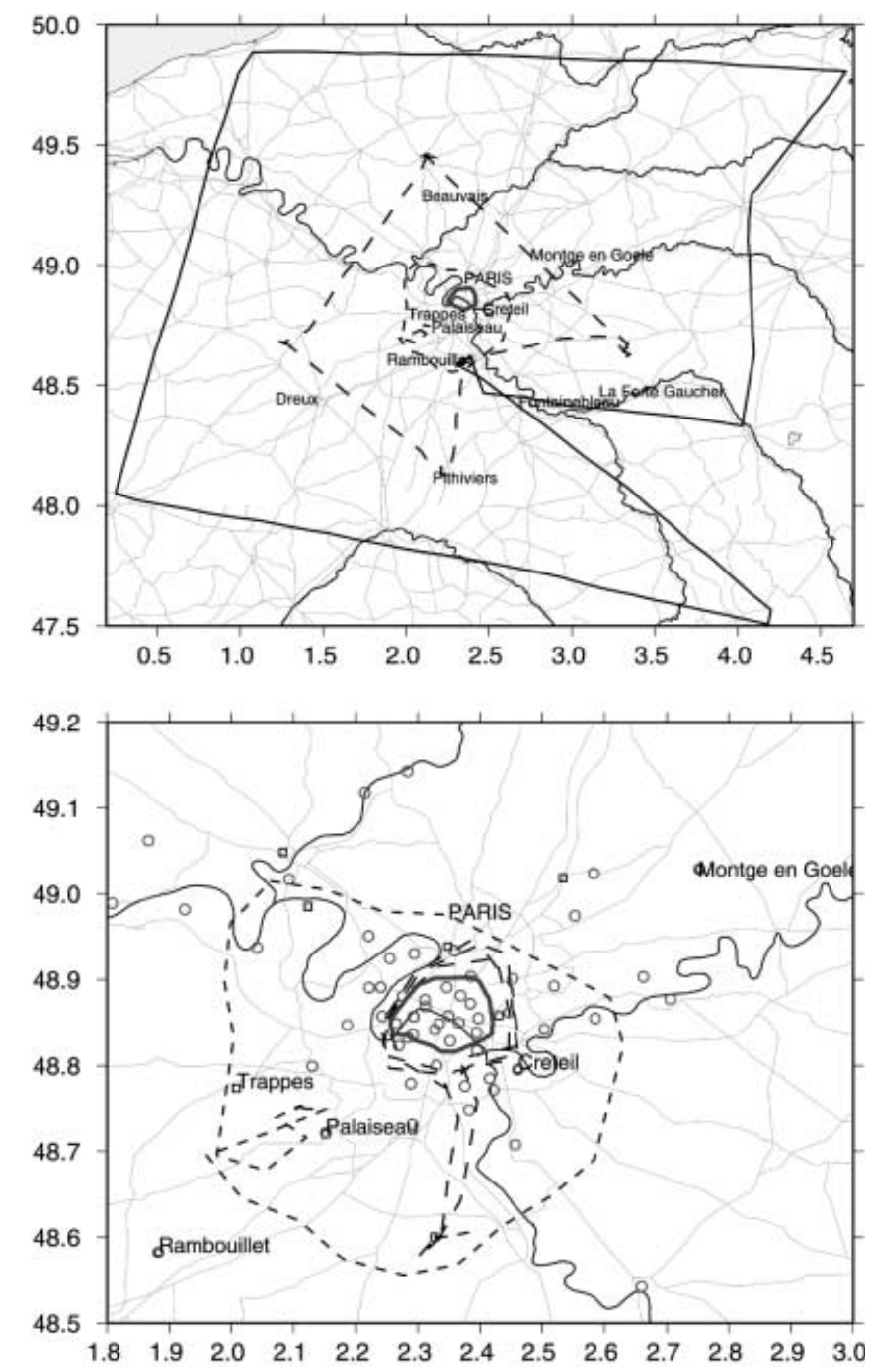

Fig. 1. The flight plans over the Paris area (the city of Paris is located at the centre of the map). The symbols, squares and circles, indicate the Météo-France and AIRPARIF surface stations (bottom), respectively. Typical flight patterns for urban (bottom), suburban (top and bottom), IdF (top and bottom) and Meso (top) flights are given by the inner solid line, dotted line and dashed lines. The city names indicate locations of the main IOPs measurements on the regional figure (bottom)

concept of oxidant $\mathrm{O}_{x}\left(\mathrm{O}_{3}+\mathrm{NO}_{2}\right)$. From measurements of $\mathrm{O}_{x}$ on the circumference and using $3 \mathrm{D}$ wind field information (measurements and model), it will be possible to derive the oxidant formation rate within the city and its export to the region.

2.2.4 The 'regular' flights. Regional aircraft soundings in the vicinity of Orleans $\left(48^{\circ} \mathrm{N} 1^{\circ} \mathrm{E}, 150 \mathrm{~km}\right.$ south of Paris) have been carried out since April 1996, and since 1999 as part of the ESQUIF project. The objective of these flights is twofold: (1) to establish a climatology of long-lived trace gas species which are radiatively active $\left(\mathrm{CO}_{2}, \mathrm{CH}_{4}\right)$ or intervene in the oxidizing capacity of the atmosphere (CO, non methane hydrocarbons), and (2) to establish boundary conditions of continental "background" rural concentrations of $\mathrm{CO}$ and non methane

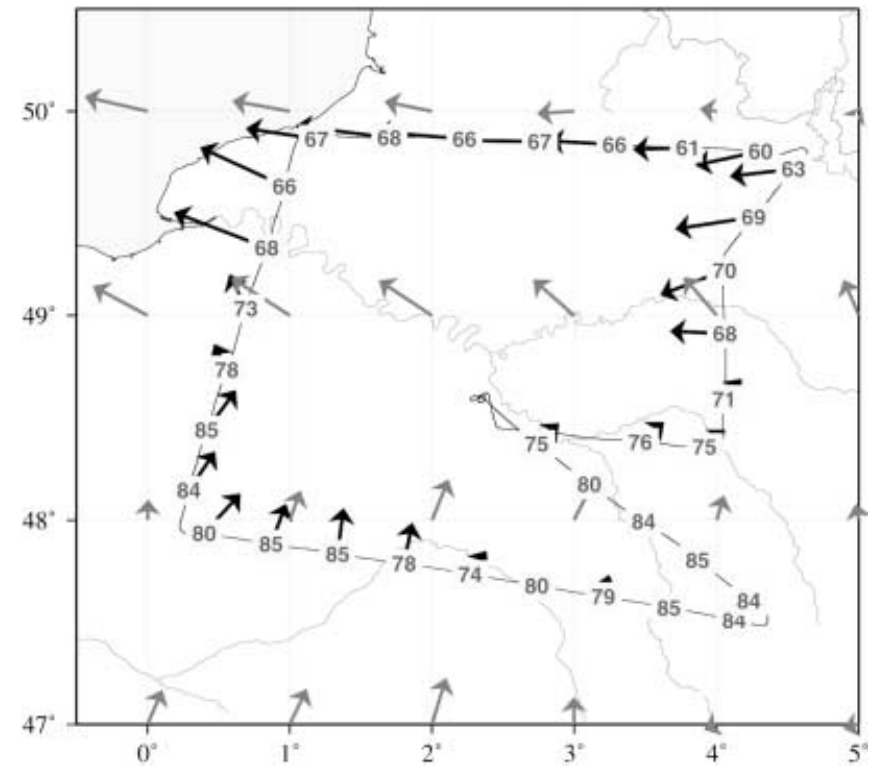

Fig. 2. A typical meso-scale flight pattern. As on Fig. 1, the city of Paris is at the centre of the map. Values displayed indicate ozone measurements (ppb) performed by the MERLIN aircraft on the 9A98 (0451-0826 UTC, $900 \mathrm{~m})$. Black vectors indicate the wind speed and direction along the flight trajectory, and grey vectors indicate the wind field modelled with the ARPEGE model

hydrocarbons (NMHCs) before their horizontal transport over the Paris Area. This is especially important in the case of NMHCs which intervene in the formation and destruction of ozone in polluted air, and can be emitted by vegetated areas outside of the urban area. The frequency of the regional flights was biweekly and the soundings were taken approximately at mid-day, between $50 \mathrm{~m}$ and $3000 \mathrm{~m}$. The total flight time was of the order of $4 \mathrm{~h}$ and the profile itself took about $1 \mathrm{~h}$. Pressure, air temperature and relative humidity were measured routinely along the profile. Pyrex glass flasks were sampled in pairs at seven different vertical levels (from 100 to $3000 \mathrm{~m}$ ) (Francey et al., 1996; Gros et al., 1998; Touaty, 1999).

The time series of $\mathrm{CO}$ vertical profiles over Orleans shows a well-defined seasonal cycle within the free troposphere, with a maximum of $190 \mathrm{ppb}$ in DecemberJanuary and a minimum of $90 \mathrm{ppb}$ in June-JulyAugust. Free-tropospheric air is representative of Western European continental background air, where industrial activities, heating and transportation emit $\mathrm{CO}$ throughout the year while $\mathrm{CO}$ is destroyed by $\mathrm{OH}$ radicals during the summer. There is also a well-defined seasonal cycle within the atmospheric boundary layer (ABL), although the variability of local sources and of their mixing within the air column during the same day does not allow the sporadic profiles to define a real "climatology" of CO near the ground. Large accumulations of $\mathrm{CO}$ (up to $350 \mathrm{ppb}$ ) below $1000 \mathrm{~m}$ are discernable in winter. In summer the $\mathrm{CO}$ gradients between the surface and the troposphere is reduced, likely due to vigorous mixing and dilution of the surface sources into the upper layers. 
Table 4. Description of the flights measurements deployed during the ESQUIF experiments

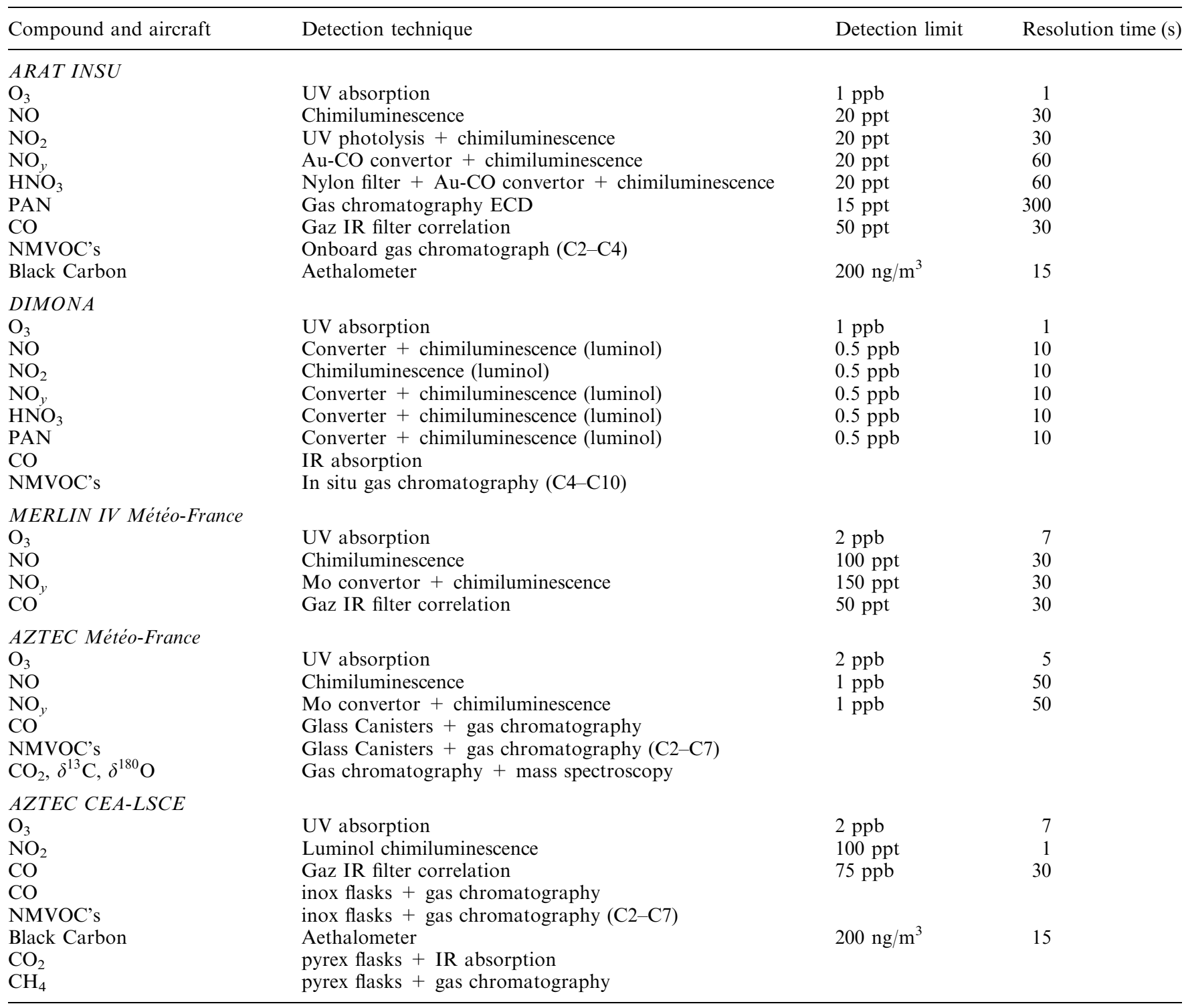

2.2.5 Ozone analyzer comparisons. Because ozone is the key compound of the campaign, different analyzers were used during the ESQUIF experiment. Thus, it was necessary to intercompare and calibrate them in order to construct a homogeneous database. The intercomparison was performed during the watch period on July, 27 1999 (between IOP7 and IOP8). Two kinds of comparisons have been carried out. The first concerned the comparison in a laboratory (LSCE) and the second was an in-flight comparison. Laboratory comparisons were made between the 'Thermo Electron' ozone analyzers (ARAT aircraft, LISA and LSCE/CEA mobile stations, see Tables 3 and 4) and a Thermo Electron calibrator 49PS analyzer. It was found that the instruments had less than $5 \%$ calibration difference. The in-flight comparisons (MERLIN, Aztec LSCE and Aztec Météo-France) were performed on July 29, 1999, at two different altitudes $(150 \mathrm{~m}$ and $900 \mathrm{~m})$ when the aircraft flew on patrol. The detailed data are still being processed.

\subsection{Ground-based measurements}

2.3.1 Network measurements. The AIRPARIF air quality network consists of more than 70 automatic stations performing continuous surface measurements of $\mathrm{O}_{3}, \mathrm{NO}$, $\mathrm{NO}_{2}, \mathrm{SO}_{2}, \mathrm{CO}$ and $\mathrm{PM}_{10}$ concentrations (denoted as small circles in Fig. 1 at three types of locations: urbanpolluted, urban background and rural.). The MétéoFrance meteorological surface network performs hourly measurements of temperature, relative humidity and pressure (hPa) at $2 \mathrm{~m}$ above ground level (AGL), along with the wind speed and direction at $10 \mathrm{~m}$ AGL (small squares on the Fig. 1). As a first step, those measurements are used for model validation (see Sect. 5).

2.3.2 Chemical and aerosols measurements. In addition to aircraft and air quality network measurements, several ground-based instruments were operated during 
the ESQUIF IOPs, and for some of them, during the whole summer.

In the centre of Paris, high frequency $(2 \mathrm{~Hz})$ measurements of $\mathrm{O}_{3}, \mathrm{NO}, \mathrm{NO}_{2}, \mathrm{SO}_{2}, \mathrm{HNO}_{3}$ and volatile organic compounds (VOC's) concentrations were made routinely by a differential optical absorption spectrometer operating in the visible and the ultra-violet range (the "SANOA" instrument, French acronym for 'Systeme d'ANalyse par Observation Active'). At the same location, measurements of $\mathrm{NO}_{2}$ photolysis rates were performed from a $\mathrm{JNO}_{2}$ radiometer. In addition, measurements were performed from the "Mobile Aerosol Station" instrument van (MAS, in Table 3) in order to characterize the urban aerosols. The equipment included sampling lines for total aerosol and carbonaceous aerosol mass concentrations, a $\mathrm{JNO}_{2}$ radiometer, an aethalometer, a nephelometer, a condensation nucleus counter and $\mathrm{PM}_{2.5}$ and $\mathrm{PM}_{10}$ devices. This van was used at several place, depending on the experiment: for example, in the Paris city centre during the IOP6 and in Saclay during the IOP7 (in conjunction with the aerosol measurements performed with the ARAT aircraft during these periods). During the entire summer of 1999 , two multi-spectral photometers (Holben et al., 1998) were used to measure aerosol spectral properties over Paris and Saclay. As aerosol optical properties are directly dependent on their age and primary sources, differences between the spectral dependency and the Angström exponent enable one to characterize the aerosol regional transport. For example, during IOP7, in which Saclay was under the Paris plume, urban aerosols were compared with rural ones. Around noon, the urban optical thickness was twice as large as the rural one, while at the end of the day, optical thickness was comparable. For this case, we hypothesize that the urban aerosol, mainly generated by car traffic (black carbon and organic carbon), was advected over Saclay.

In the suburbs of Paris, integrated ozone content was measured in Verrières $(20 \mathrm{~km}$, southwest of Paris) by a spectrometer operating in the visible and the ultra-violet (SAOZ, French acronym for "Système d'Analyse par Observation Zénithale") twice a day, at dusk and dawn. This integrated ozone column is an important input parameter for an exact calculation of $\mathrm{J}\left(\mathrm{O}_{3}^{1 D}\right)$ photolysis frequencies with radiative transfer models. In addition, aerosols size distributions and composition (as well as their optical properties) were characterized in Saclay (25 km, southwest of Paris) using a nephelometer, an aethalometer and a condensation nuclei counter as well as total aerosol filters and black carbon filters.

2.3.3 Backscatter lidar measurements. Two upwardlooking backscatter lidars operating at a wavelength of $0.53 \mu \mathrm{m}$ were deployed in the centre of Paris and in Palaiseau ( $25 \mathrm{~km}$ southwest of Paris). The lidar was intended to document some of the key parameters relevant to (1) the ABL dynamics, i.e. the ABL depth and entrainment zone depth, (2) radiative budget i.e, optical depth, and (3) oxidation/production of photochemical species, i.e., extinction coefficient profiles (which are relevant to the actual photolysis rate), with a vertical resolution of $30 \mathrm{~m}$. In addition, a pyranometer and a pyrgeometer (for measurements of infrared and longwave radiations), a sonic anemometer (turbulence), and pressure, humidity and temperature measurements were performed simultaneously to lidar measurements at Palaiseau. In addition, a differential absorption lidar (ALTO, acronym for "Airborne Lidar for Tropospheric Ozone", Ancellet and Ravetta, 1998) was operated during the IOPs of summer 1999 at the Palaiseau site in order to continuously record the tropospheric ozone profile up to $5 \mathrm{~km}$ height.

2.3.4 Soundings. The vertical thermodynamical structure of the atmosphere in the Paris area was documented by means of soundings performed by Météo-France in Trappes $(25 \mathrm{~km}$ southwest of Paris). Temperature, relative humidity, pressure and wind speed and direction soundings were measured twice daily at 0000 and 1200 UTC. During some IOPs, additional soundings were performed every three hours at the Trappes site. From temperature, specific humidity and wind measurements, Richardson number and potential temperature profiles can be obtained which are then used to compute the diurnal evolution of the depth of the ABL. The ABL depth cycle can in turn be compared to that derived from lidar measurements.

\section{Overview of numerical models}

\subsection{Meteorological models}

Two meso-scale models, MERCURE (Souffland, 1985) and Meso-NH (Lafore et al., 1998) will be used to perform simulations of the meteorological conditions on domains ranging from $100 \times 100 \mathrm{~km}^{2}$ to $500 \times 500 \mathrm{~km}^{2}$, centred on Paris. Horizontal and vertical resolutions may be adapted from 1 to $10 \mathrm{~km}$ and from 10 to $50 \mathrm{~m}$, respectively. These models have already been used for simulating the air flow over Paris (Menut et al., 1999; Tulet et al., 1999 for Mercure and Meso-NH, respectively). Realistic meteorological boundary conditions for these meso-scale models will be provided by the ECMWF and ARPEGE (Météo-France) analyses. In addition, a zoomed version of the Laboratoire de Météorologie Dynamique (LMD) general circulation model (LMDz) was also used. The size of the grid cell characterizing Paris in this model is $50 \times 50 \mathrm{~km}^{2}$. The grid size increases away from the centre of the domain, and the model uses ECMWF for boundary conditions.

\subsection{Chemistry-transport models}

The meteorological fields provided by the models described in the previous section will be used as inputs to the models presented here. At the local scale, the urban CHIMERE model (Vautard et al., 1999; Menut et al., 2000) was used as a forecast and analysis tool. 
It is a more realistic adaptation of the box model approach proposed by Jin and Demerjian (1993) to the Paris area. It uses the MELCHIOR chemical mechanism. At the meso-scale, the models used will be MesoNHC (Tulet et al., 1999), A A $_{3}$ (Jaecker-Voirol et al., 1998) and POLLUTO, which are coupled to meteorological models Meso-NH, MERCURE and ECMWF data respectively. The chemical mechanism MoCA (Aumont et al., 1997) of $\mathrm{A}_{3} \mathrm{UR}$ has already been tested over Paris.

In addition, modified versions of CHIMERE, with an Eulerian grid, are currently being developed: namely a meso-scale version to perform simulations on a $150 \times 150 \mathrm{~km}^{2}$ domain around Paris with a horizontal resolution from 6 to $10 \mathrm{~km}$ and a continental version over Western Europe, with a $1 / 2$ degree resolution. Modelling results presented here have been performed with the meso-scale chemistry transport model (CTM) POLLUTO. POLLUTO, is a three-dimensional chemistry-transport model using a cartesian mesh. The domain is defined in order to have the city of Paris (the most urbanized area) at the centre of the horizontal mesh and is composed of $15 \times 9 \times 6$ nodes in the $x-y-z$ directions, respectively. The model is forced by the ECMWF first guesses (6-h forecasts). These meteorological fields are re-interpolated over the studied domain in time (one hour frequency) and space (with an horizontal resolution of $10 \mathrm{~km}$ and ranging from 0 to $2700 \mathrm{~m}$ vertically). To account for thermodynamic processes, POLLUTO requires mass fluxes, temperature, density, specific humidity and cloudiness (for chemistry) as inputs. At each grid point, turbulence parametrizations are used in order to retrieve vertical turbulent diffusivity profiles, surface friction velocity for dry deposition (Wesely, 1989). The gas-phase chemistry mechanism is MoCA and the adjoint part of the whole model is developed, and currently used for sensitivity analysis (see Menut et al., 2000 for the adjoint principle). Hourly values of surfacic anthropic emissions are given for 15 primary pollutants, using two data sources: the CITEPA (1993) inventory, providing annual totals of emissions of $\mathrm{NO}_{x}, \mathrm{SO}_{2}, \mathrm{CO}, \mathrm{CH}_{4}$ and NMVOCs (non speciated), and the GENEMIS (1994) data base, used for NMVOC speciation and temporal disaggregation of annual totals to hourly values.

The MOCAGE model (Peuch et al., 1999), currently developed at Météo-France/CNRM, will be used to provide chemical boundary conditions at continental scale. Finally, as a complement to all previous Eulerian models, the Lagrangian model, MELCHIOR was used for analysis of pollutant trajectories over Europe.

\section{IOP2 of ESQUIF: data analysis}

The ESQUIF experiments performed during summer 1998 have been designed to address more specifically the following questions: (1) what are the relative contributions of local production and long-range transport to the ozone concentrations measured over the Paris area during pollution events and (2) what is the impact of the vertical boundary layer structure on ozone build-up over the Paris area? In this section, we perform preliminary analyses in order to illustrate how ESQUIF data can be used to address these questions.

We focus on IOP2 which lasted three days, from Friday to Sunday 7-9 August 1998 (hereafter called 7A98, 8A98 and 9A98, respectively, Table 5). This period (including 10 and 11 August, 1998) corresponded to the highest ozone concentrations recorded during the whole summer of 1998. As the experimental set-up was optimum during 7A98, 8A98 and 9A98 (including aircraft measurements), we focus our analysis on these three days.

In order to understand the origin of air masses advected into the Paris area, a series of seven day backtrajectories were calculated. These trajectories used the wind field as diagnosed by ECMWF first guesses. During the convective period, air parcels are well mixed within the boundary layer. Hence neither constantaltitude trajectories nor trajectories following the mean 3-dimensional wind field would be realistic. In order to overcome this problem, air trajectories were assumed to undergo a random altitude change every hour during the convective period (0900-1800 UTC). They were nevertheless bounded to stay between 0 and $1500 \mathrm{~m}$. Fifty backtrajectories are calculated in this way (due to the convective processes, an ending point does not correspond to the same origin. In order to take these various origins into account, 50 trajectories are studied). Figure 3 represents these "back-plumes" ending in Paris during the three IOP days and the day before. On 6A98 and 7A98, the air mass has a maritime origin, while on 9A98 it has travelled over the British Isles as well as Belgium, the Netherlands and Luxemburg. We thus expect that on day 9A98 a significant part of ozone measured over Paris originated from precursors emitted over Northern Europe, while on day 7A98, most of the pollution was locally produced.

Table 5. Overview of the meteorological conditions over Paris and maximum surface ozone concentrations in representative locations during the IOP2. The background and plume concentrations are from the AIRPARIF stations in Montge en Goele and Rambouillet, respectively. The times when the maximum of ozone occurred are given in parentheses

\begin{tabular}{|c|c|c|c|}
\hline Day & 7A98 & 8A98 & 9A98 \\
\hline \multicolumn{4}{|c|}{ Meteorological conditions over Paris } \\
\hline Wind direction (from) & $\mathrm{N}-\mathrm{E}$ & $\mathrm{E}$ & $\mathrm{S}$ to $\mathrm{E}$ \\
\hline Wind speed at $10 \mathrm{~m}\left(\mathrm{~m} \mathrm{~s}^{-1}\right)$ & 1.4 & 1.3 & 1.8 \\
\hline Maximum ABL depth (m) & 800 & 2300 & 2800 \\
\hline Temp. at $2 \mathrm{~m}\left({ }^{\circ} \mathrm{C}\right)-$ low & $16.5(05)$ & $17.5(06)$ & $18.7(05)$ \\
\hline Temp. at $2 \mathrm{~m}\left({ }^{\circ} \mathrm{C}\right)-$ high & $31.0(16)$ & $35.3(16)$ & $35.0(15)$ \\
\hline \multicolumn{4}{|c|}{ Ozone concentrations (ppb) over the Ile de France (IdF) } \\
\hline Paris & $60(16)$ & $\begin{array}{l}85(12) \\
55(16)\end{array}$ & $95(16)$ \\
\hline Urban plume & $125(16)$ & $90(12)$ & $120(16)$ \\
\hline Background & $55(15)$ & $\begin{array}{l}85(16) \\
70(12) \\
55(16)\end{array}$ & $90(16)$ \\
\hline Production by Paris & 70 & $20-30$ & 30 \\
\hline
\end{tabular}




\subsection{Regional ozone formation and continental transport}

In order to quantify the amount of ozone produced in large cities such as Paris, one cannot use measurements taken within the Paris city limits since ozone formation is usually maximum in the city plume, about $50 \mathrm{~km}$ downstream of Paris city itself (see e.g. Tulet et al., 1999).

On 7A98, the urban plume was observed southwest of Paris from aircraft and surface measurements. In this region, ozone concentrations measured by the MERLIN aircraft (Table 6) at about $500 \mathrm{~m}$ AGL reached about $110 \mathrm{ppb}$ at the end of the afternoon, while those encountered in the northeast side of the city were about 60-70 ppb. Therefore, photochemical ozone production from local emissions was at least about $50 \mathrm{ppb}$ during this day. The aircraft circuited six times around the city during the afternoon on the same trajectory. Thus, at each trajectory point, a time series of the ozone concentrations, can be plotted.

We represent in Fig. 4 this time evolution for four selected points. The first (second) location, in the northeast (southwest) of Paris, is used to characterize the ozone concentration upstream (downstream) of Paris. The other two locations (southeast and northwest of Paris) are chosen so as to document ozone concentrations in the cross-wind direction. These locations are further referred to as NE, SW, SE and NW (Fig. 4). On the lee side, downwind of Paris, the ozone increase is very pronounced while on the upwind side concentrations do not vary much during the afternoon. At the two other locations, concentrations reach intermediate values, with a peak occurring earlier than in the plume. The same behaviour is observed from ground stations. At Montgé en Goële (about $40 \mathrm{~km}$ NE of Paris), peak concentrations reach about $60 \mathrm{ppb}$ while at Rambouillet (southwest of Paris), peak values are of the order of $125 \mathrm{ppb}$ (see Fig. 8). In the urban area, concentrations are similar to upstream values.

On 8A98, the surface concentrations measured at all stations peaked around 1200 UTC which is quite unusual (as peaks are generally observed around 1500 UTC over the Paris area). A second maximum of
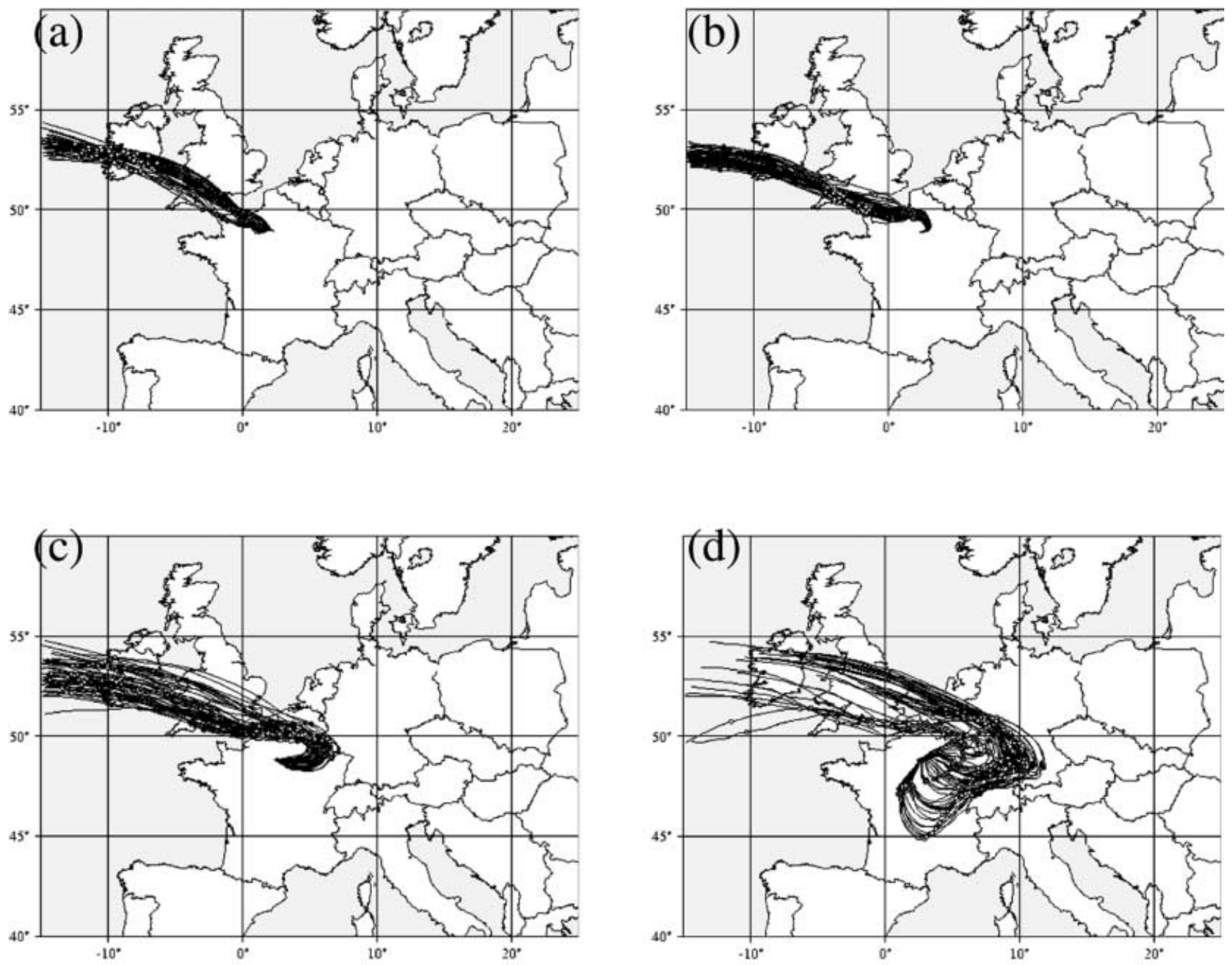

Fig. 3a-d. Back-trajectories ending in Paris on a 6 August 1998, b 7 August 1998, c 8 August 1998 and d 9 August 1998 
Table 6. Aircraft operations during the IOP2. 'Loops' refers to the number of circuits made around Paris during the flight

\begin{tabular}{llllll}
\hline Aircraft & Day & $\begin{array}{l}\text { Time period } \\
(\mathrm{UT})\end{array}$ & Flight type & Loops & Levels (m) \\
\hline MERLIN & 7A98 & $0609-0711$ & Suburban & 1 & 500 \\
& 7A98 & $1224-1540$ & Suburban & 6 & 500 \\
& 8 A98 & $0454-0832$ & Meso & 1 & 900 \\
& 8A98 & $1232-1448$ & IdF & 1 & 500 \\
& $9 A 98$ & $0451-0826$ & Meso & 1 & 900 \\
AZTEC-MF & 9A98 & $1254-1513$ & Suburban & 5 & 500 \\
& 7A98 & $0725-0817$ & Urban & 3 & $300,900,1500,1650$ \\
& 7A98 & $1444-1542$ & Urban & 3 & $300,900,1500,1650$ \\
& 8 A98 & $0558-0837$ & IdF & 1 & $165,330,500$ \\
& 8 A98 & $1158-1255$ & Suburban & 1 & 500 \\
AZTEC-LSCE & 8A98 & $1443-1534$ & Suburban & 1 & 500 \\
& $9 A 98$ & $0556-0852$ & IdF & 1 & $165,500,1650$ \\
& 9A98 & $1314-1625$ & IdF & 1 & $165,500,1650$ \\
& 7A98 & $0727-0919$ & IdF & 1 & $300,600,1500$ \\
& $1320-1522$ & IdF & 1 & $300,600,1500$ \\
\hline
\end{tabular}

ozone concentration is observed at the expected time (1600 UTC). In the afternoon, background values in Montgé en Goële are larger than on 7A98. The plume occurs more to the west, due to light easterlies. By comparing upstream and downstream values (not shown) we conclude that the ozone production is approximately $25 \mathrm{ppb}$.

On 9A98, the evolution of the ozone concentration measured at $500 \mathrm{~m}$ AGL during the 5 'Agglo' flights exhibit similar trends in the NE, NW and SW locations (Fig. 4), the values in the SW location being approximately $10 \mathrm{ppb}$ larger. The background concentrations are much larger than on 7A98 and 8A98. Mean ozone concentrations differences between downwind and upwind of Paris are about $30 \mathrm{ppb}$.

Concentrations of ozone measured along the Meso flight were also very interesting (Fig. 2): The flight altitude was about $900 \mathrm{~m} \mathrm{AGL}$, above the rising mixed layer, early in the morning. High concentrations (80$90 \mathrm{ppb}$ ) were found in the southern branch while in the northern branch concentrations were moderate $(60$ $70 \mathrm{ppb}$ ). The explanation of such trends can again be given in terms of backtrajectories.

Figure 5 shows the backtrajectories, calculated with the same model as above, arriving at the northeast and southwest corners of the Meso flight trajectory. The air mass arriving at the northeast corner originates from the ocean, before spending about $24 \mathrm{~h}$ above continental polluted areas (Benelux). The air mass arriving at the southwest corner has travelled over central England, Benelux, western Germany and central-eastern France. It has spent more than four days over continental areas, which apparently causes the higher ozone concentrations. It is noteworthy that during the two days before arrival, the air masses arriving at the southwestern corner of the Paris metropolitan area, essentially cross rural areas, but with potentially high biogenic emissions, especially given the hot temperatures at this time (about $30-35{ }^{\circ} \mathrm{C}$ ). The relative importance of biogenic versus anthropogenic continental emissions will be investigated within the ESQUIF project on a modelling basis, and will be reported in a future article.
Fig. 4. Aircraft measurements of ozone, on 7 A998 and 9A98, at $500 \mathrm{~m}$ AGL. The central box presents the city of Paris with the 'suburban' flight trajectories superimposed. Also shown are the four representative locations selected to conduct the pollution analysis (NW, NE, SE and SW, see text for explainations). The time evolution of the ozone concentration measured in these locations are presented in the surrounding boxes 


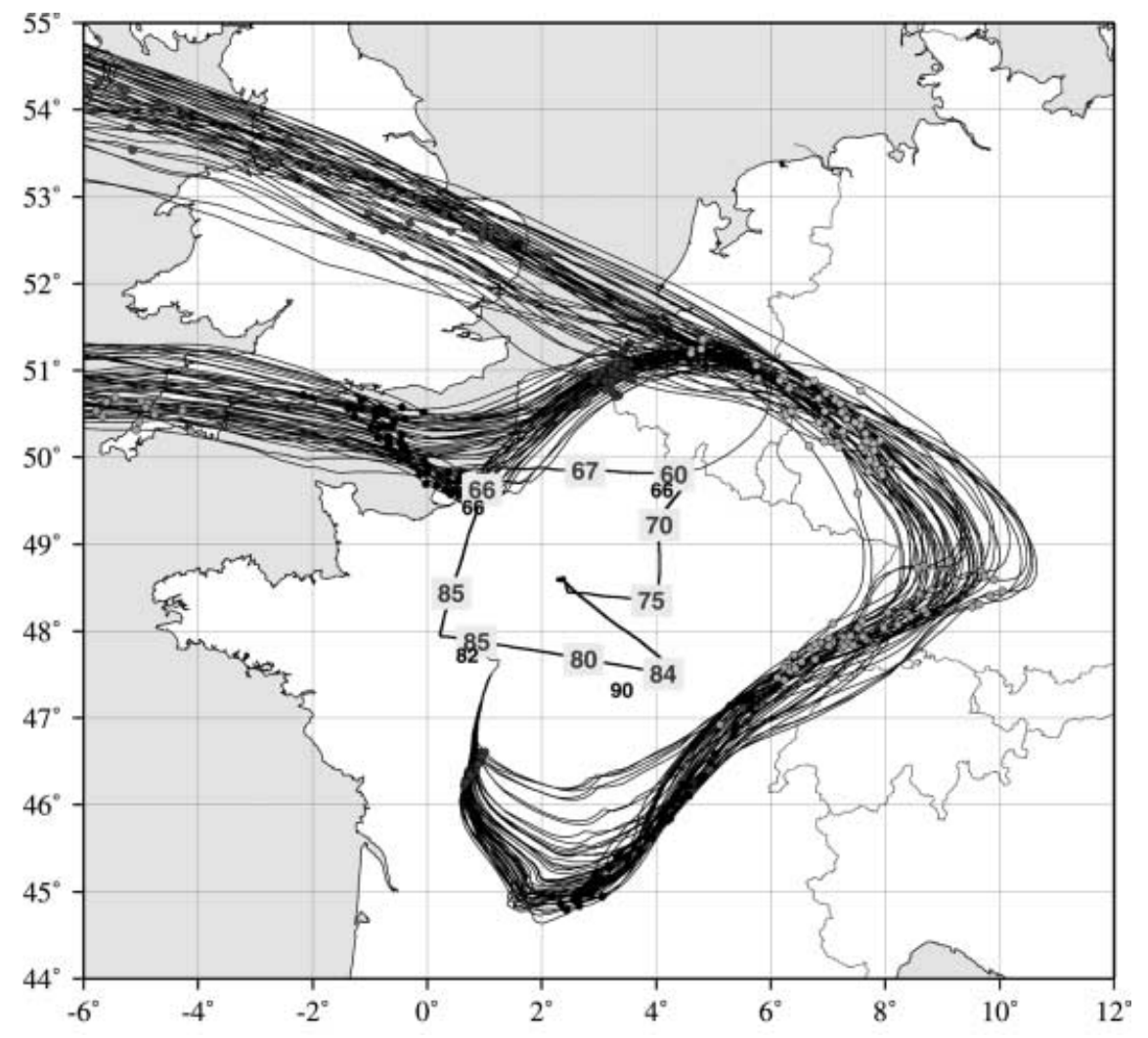

Fig. 5. Aircraft measurements performed during the Meso flight performed on 9A98 during the morning (0451-0826 UTC): boxes indicate the ozone concentrations (ppb) at $900 \mathrm{~m}$. The two sets of backtrajectories ending at the northeast (with $\left[\mathrm{O}_{3}\right]=66 \mathrm{ppb}$ ) and southwest (with $\left.\left[\mathrm{O}_{3}\right]=82 \mathrm{ppb}\right)$ corners of the Meso flight (9A98 at 0600 UTC) are estimated from back-trajectory modelling. Each point corresponds to $24 \mathrm{~h}$ steps before the ending time, showing the air masses trajectories and the time spent above urban and/or rural areas

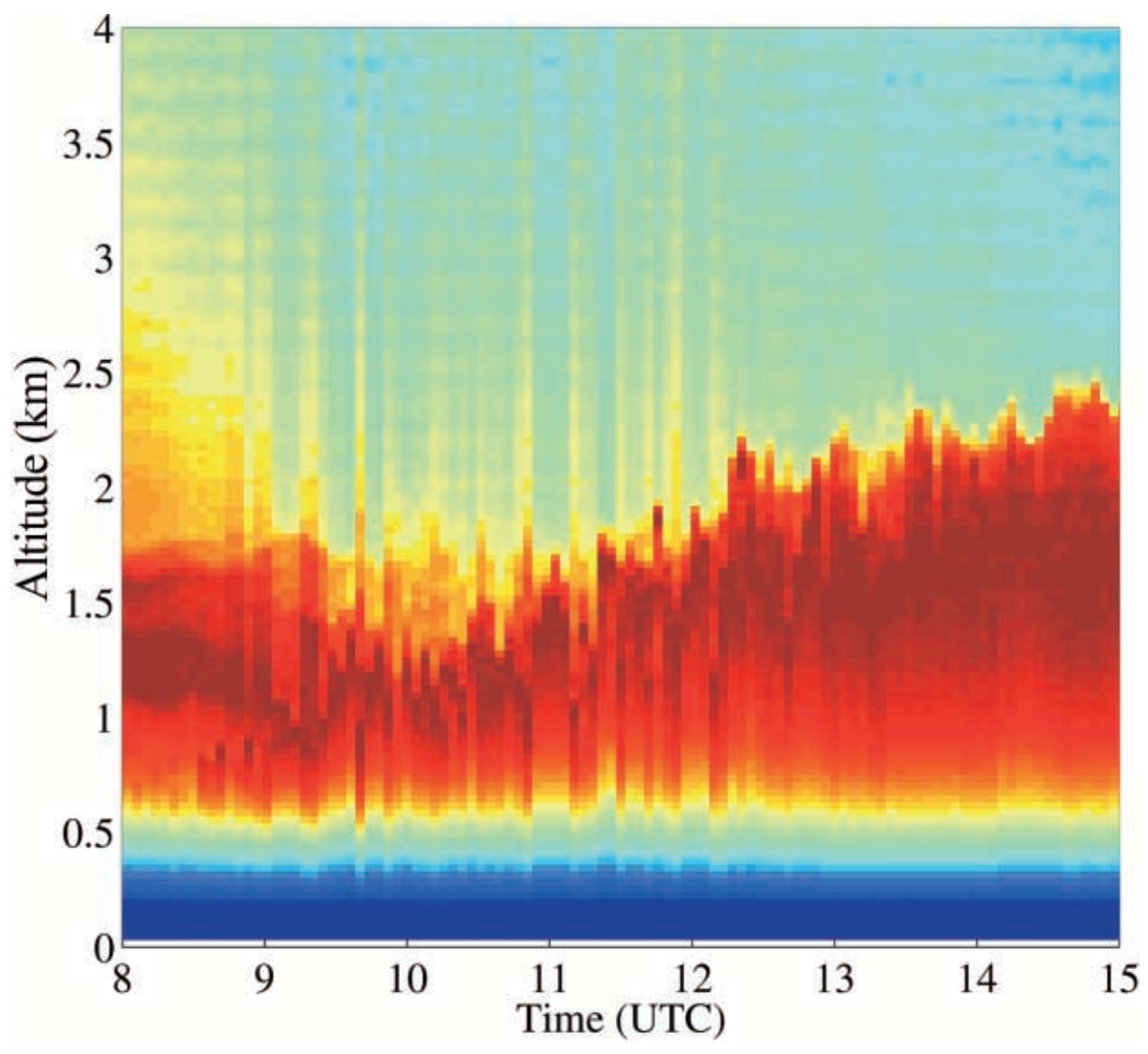

Fig. 6. Atmospheric reflectivity at a wavelength of $0.53 \mu \mathrm{m}$ obtained from the backscatter lidar located in Palaiseau during 8 August, 1998 

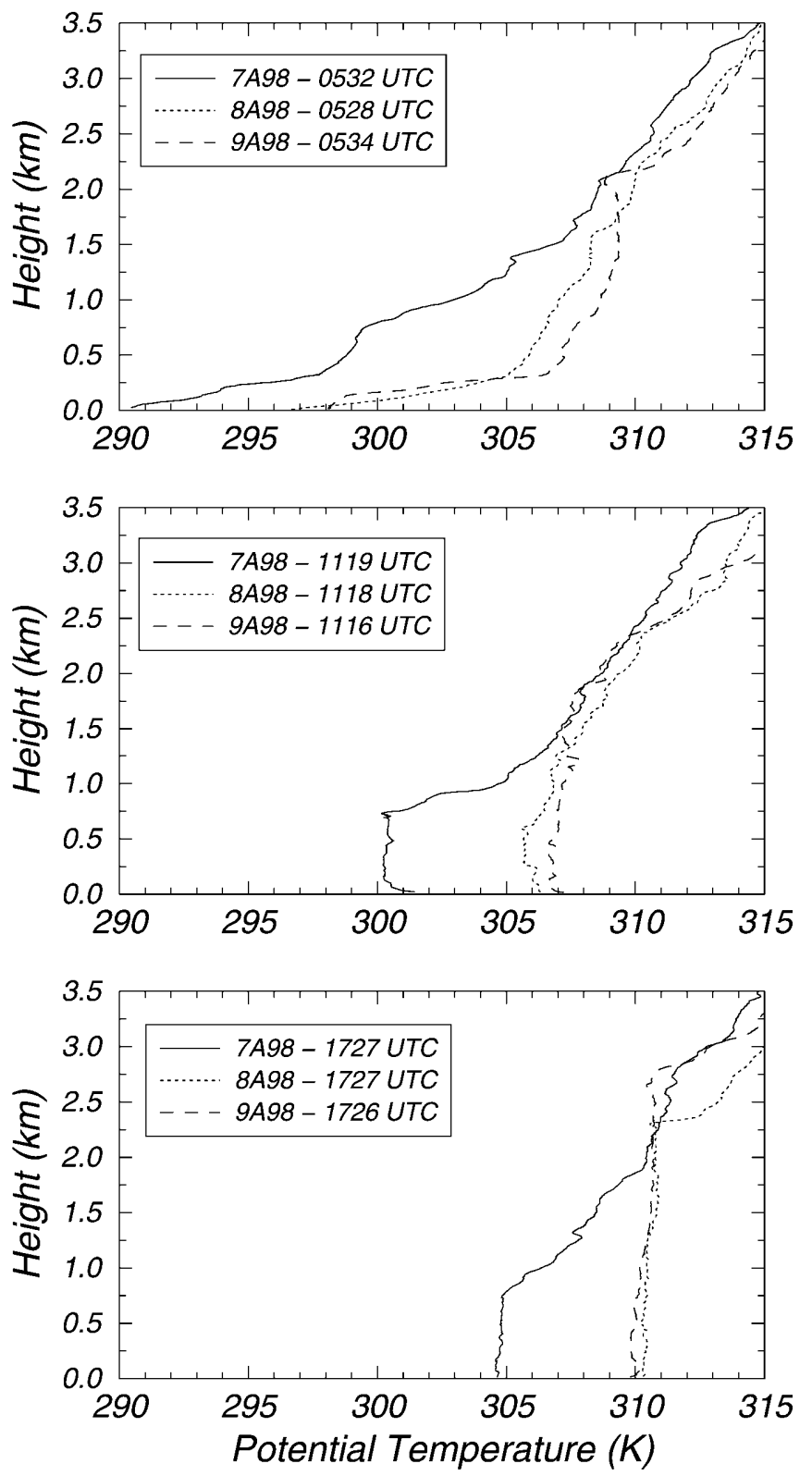

Fig. 7. Potential temperature soundings performed in Trappes, $30 \mathrm{~km}$ to the southwest of Paris on 7-9 August, 1998

The important point here is that these measurements demonstrate that high ozone concentrations can be found over rural areas remote from important urban sources, and eventually be transported into urban areas, together with other non-oxidized precursor species.

\subsection{Impact of the vertical boundary layer structure for the ozone concentrations measured over the Paris area}

In addition to horizontal transport and chemical processes, the accumulation or dispersion of pollutants emitted at the surface is also driven by the convection processes within the ABL.

On 7A98, the ozone concentrations in Montgé en Goële and Paris are moderate (see previous section).
However, the concentrations measured in Rambouillet at the surface and at $500 \mathrm{~m}$ AGL were the largest measured during the IOP. On this day, the maximum ABL depth is observed at $800 \mathrm{~m}$ around 1200 UTC which is much shallower than on 8A98 and 9A98 and is not representative of what is generally observed during the summer. Moreover, it remains constant for the rest of the afternoon. Meso-scale simulations were made with the Meso-NH model showing that this atypical situation was mainly due to large-scale subsidence over the Paris area. It is interesting to notice that the low ABL height was associated with the strongest ozone gradients between the city and the plume, although we cannot conclude directly that low ABL height favours local ozone production. Indeed several effects are combined: the first IOP day, 7A98, is a Friday while the rest of the IOP occurs during the weekend, for which the emission pattern is significantly different; the second is that urban ozone concentrations can be lower when the $\mathrm{ABL}$ is low due to ozone titration by $\mathrm{NO}$ emissions; and third, in a shallow ABL higher aerosol concentrations may alter the photolysis processes in the urban area, making the city-plume gradient higher. All these hypotheses will be tested using numerical modelling, and will be reported in future articles.

On 8A98, the 0830 UTC temperature sounding (not presented here) exhibited a synoptic inversion at $1300 \mathrm{~m}$ which was also observed on the lidar-derived atmospheric reflectivity (Fig. 6) measured in Palaiseau (approximatively halfway between Paris and Rambouillet). The diurnal evolution of the lidar signal shows the maintenance of an elevated polluted layer (from 600 and $1300 \mathrm{~m}$ ) between 0800 and 0900 UTC which was decoupled from the surface by the nocturnal inversion (the height of the nocturnal temperature inversion was observed at $600 \mathrm{~m}$ on the 7A98 2318 UTC sounding). Around 1000 UTC, the residual layer was absorbed by the growing ABL. Surface ozone concentrations measured in Rambouillet did not exhibit a sudden increase at this time period which could mean that the ozone concentration in the residual layer was small. The surface ozone concentration in Rambouillet increased until 1200 UTC while the ABL height rose to approximately $2300 \mathrm{~m}$ (from lidar data and temperature soundings) until 1700 UTC. The concentration decrease between 1200 and 1700 UTC could be explained by entrainment of low ozone background concentration into the ABL. This is in agreement with the fact that the previous day's boundary layer was rather low and that air masses entrained into the ABL thus have not encountered for the chemical ozone production the day before.

On 9A98, the ozone concentration in Rambouillet and the ABL depth increased until 1700 UTC (Fig. 8 and Fig. 7, respectively). However, the previous day's ABL was also high, explaining high ozone concentrations found at high altitude. Ozone peaks were much later than the previous day, since the dilution effect was not as effective on this day. We also note an increase, during the afternoon, in the background ozone (see in Fig. 8 the Montgé-en-Goële station), which could also explain 

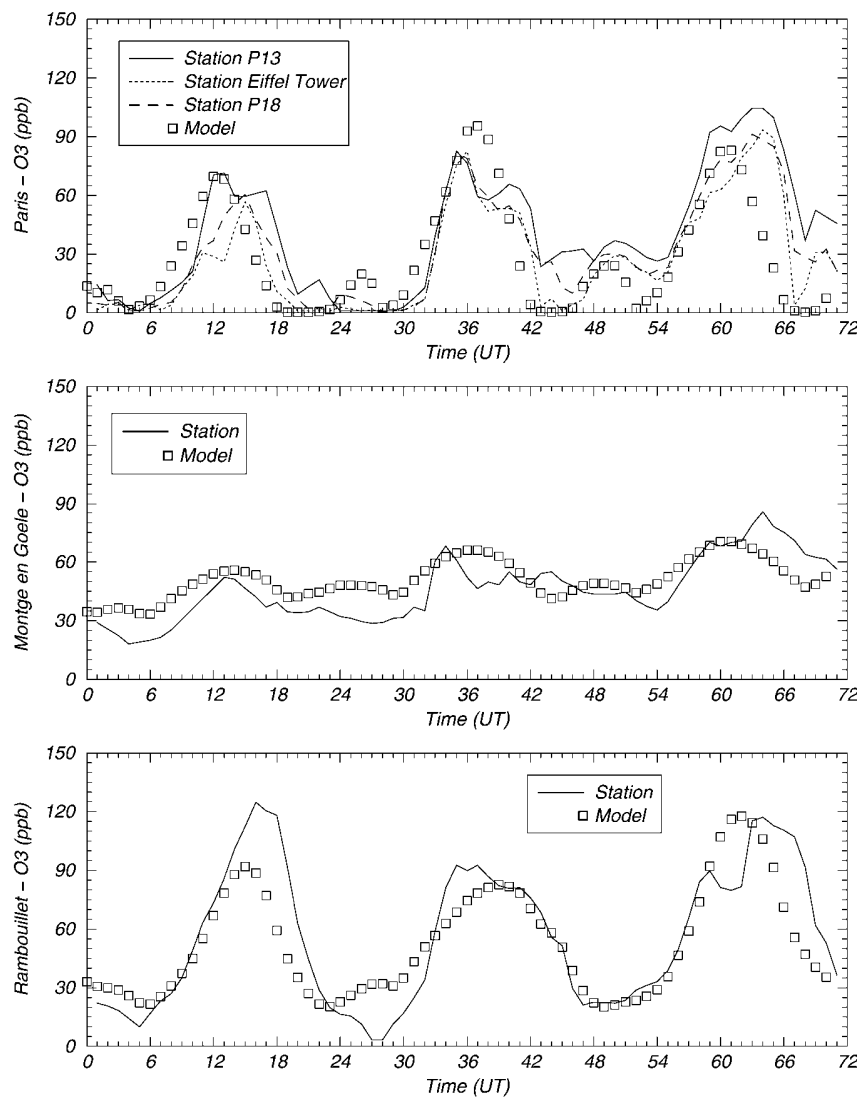

Fig. 8. Surface ozone concentrations (ppb) measurements by AIRPARIF from 7 to 9 August, 1998, (from 0 to 72 h) in Paris (top), Montge-en-Goële (middle), and Rambouillet (bottom). The Montgeen-Goële and Rambouillet suburban stations are located to the northeast and southwest of Paris, respectively. Results from the CTM model are added at each location for comparison with in situ measurements

the general increase of all ozone concentrations at the end of the afternoon. Again, definitive conclusions can only be given after numerical simulation of the episode using both regional and continental scale models.

\section{IOP2 of ESQUIF: model analysis}

The first goal of analysis modelling is to determine if CTM models are able to reproduce a complex pollution event such as the one observed during IOP2. The simulation was performed from 7A98 (0000 UTC) to 9A98 (2300 UTC). In order to account for small-scale surface heterogeneities, ECMWF profiles were interpolated to the surface using observed temperature and pressure data (from surface stations). Ozone concentrations resulting from the three-dimensional simulations are compared to those measured by surface stations on an hourly basis. In Fig. 8, comparisons are displayed for Paris (top), Montgé-en-Goële, northeast of Paris (middle), and Rambouillet, southwest of Paris (bottom). For the three locations, the agreement is fair over the three days. In Paris, on 7A98 and 8A98, concentrations are representative of the averaged observed concentrations, and on 9A98, in Paris, one notes a model underestimation at the end of the day. In Montgé-en-Goële, the model fits the observations well which are representative of background ozone advected over the whole simulated domain. Over Rambouillet, on 8A98 and 9A98, the model fits the surface ozone concentrations well, but some discrepancies appear on 7A98 where the plume intensity is underestimated. In order to understand this underestimation, we turn to Fig. 9 which displays a map of simulated ozone (in ppb, at $z=500 \mathrm{~m}$ AGL, on 7A98 and at 1500 UTC) over the Paris area.

These simulated ozone values are compared to aircraft ozone measurements, performed at the same period. The plume amplitude is well reproduced, but it is shifted slightly southward compared to observations. The discrepancies between modelled and observed values may be explained in terms of the mean meteorological forcing fields used: the ECMWF inputs correspond to the mean flow over the whole domain, without topography at small scale. Errors induced using these meteorological fields may be of the order of a few percent for wind speed and direction. The next step to improve the analyses performed with POLLUTO will be to use simulations made by a fully mesoscale model, such as Meso-NH in order to account for small-scale topography and more accurate turbulent effects. This step is currently in preparation.

\section{Summary and conclusion}

The objectives and the experimental set-up of the ESQUIF project have been presented. Numerous ground and airborne measurements have been acquired in the course of 10 IOPs, which cover a variety of meteorological situations leading to air pollution in the region of Paris. This project is part of a series of European projects dedicated to atmospheric pollution which have been undertaken recently. With respect to the other projects, one outstanding goal of the ESQUIF project is to implement a thorough data base which would include the measurements as well as model simulations. This data base exists (http://moebius.polytechnique.fr/resquif/) and will be available shortly to the scientific community interested in atmospheric pollution studies.

We have presented preliminary results obtained during the second IOP of ESQUIF, in August 1998. The study conducted here demonstrates that only a continental-scale approach enables a thorough understanding of atmospheric photochemical pollution over a strongly urbanized area such as Paris. Indeed, strong pollution events were diagnosed to be influenced by dynamical and chemical processes at different scales. A major reason for this is certainly the absence of marked orography. For the situations documented here, it was shown that, besides surface emissions, the major factors driving pollutants concentrations were continental-scale transport and convective activity.

The main result of this study is to show that, combining modelling and experimentation, we could 


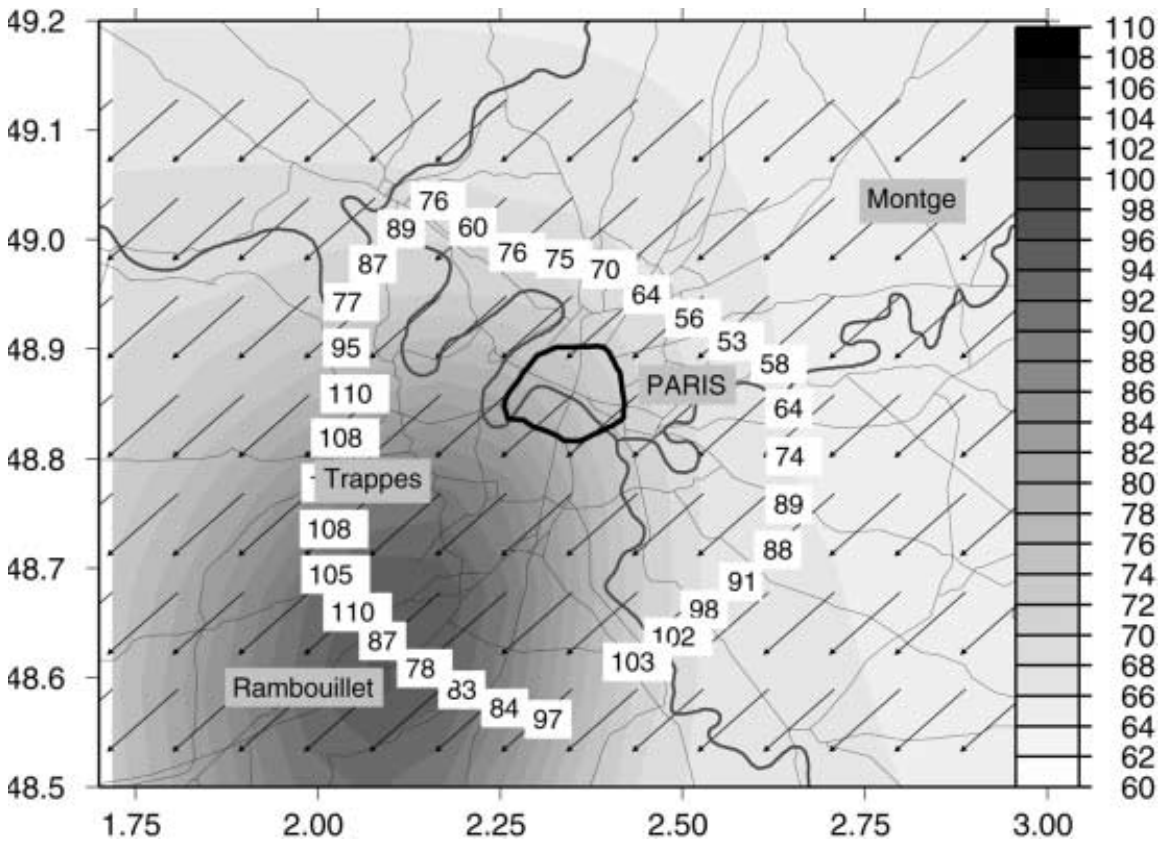

Fig. 9. Measurements and model comparison for $\left[\mathrm{O}_{3}\right](\mathrm{ppb})$ concentrations on $7 \mathrm{~A} 98$ at $500 \mathrm{~m}$ AGL and 1500 UTC. The city of Paris is at the centre of the model domain, and the concentrations are representative of the vertical box model at $z=500 \mathrm{~m}$. The aircraft measurements were performed during a suburban flight (7A98, from 1430 to 1500 UTC, with the MERLIN aircraft, see Table 6) and $\left[\mathrm{O}_{3}\right](\mathrm{ppb})$ measurements are superimposed along the flight trajectory. Wind vectors are from ECMWF data identify the contribution of local production versus regional transport to the ozone peak. Using this combined approach, we have shown that on 7A98, the pollution event is mainly due to local production, whereas on 9A98, high ozone concentrations are due both to local production and regional ozone transport.

Acknowledgements. This work was supported by the Institut Pierre-Simon Laplace (IPSL), the Ministère de l'Aménagement du Territoire et de l'Environnement, the Conseil Régional d'Ile-deFrance, the Commissariat à l'Energie Atomique, and Elf-Aquitaine. We are indebted to all our colleagues from LSCE, SA, LMD, LISA, METEO-FRANCE and AIRPARIF who have operated the instruments during the campaign.

Topical Editor J.-P. Duvel thanks D. Steyn and M. Brown for their help in evaluating this paper.

\section{References}

Ancellet, G., and F. Ravetta, Compact airborne lidar for tropospheric ozone: description and field measurements, Appl. Optics, 37, 5509-5521, 1998.

Aumont, B., A. Jaecker-Voirol, D. Martin, and G. Toupance, Tests of some reduction hypothesis in photochemical mechanisms: application to air quality modeling in the Paris area, Atmos. Environ., 30, 2061-2077, 1997.

Centre Interprofessionel Technique Etude de la Pollution Atmopshérique (CITEPA), Inventaire des émissions de $\mathrm{SO}_{2}, \mathrm{NO}_{x}$, poussières, $\mathrm{COVNM}, \mathrm{CH}_{4}$ dans l'atmosphère en Ile-de France en 1990, Etude, 136, Paris, France, 1993.

Doran, J. C., et al., The IMADA-AVER boundary layer experiment in the Mexico city area, Bull. Am. Meteorol. Soc., 79, 2497-2508, 1998.

Dupont, E., L. Menut, B. Carissimo, J. Pelon, and P. H. Flamant, Observations of the atmospheric boundary layer in Paris and its rural suburbs: the ECLAP experiment, Atmos. Environ., 33, 979-994, 1999.

Francey, R. J., et al., Global atmospheric sampling laboratory (Gaslab): supporting and extending the Cape Grim trace gas programs, Baseline 1993, 8-29, 1996.
Generation of European Emission Data for Episodes (GENEMIS) project EUROTRAC Annual report 1993, part 5, EUROTRAC Int. Sci. Secretariat, Garmish-Partenkirchen, Germany, 1994.

Gros, V., R. Sarda-Esteve, B. Bonsang, and M. Ramonet, Mesure du monoxyde de carbone par chromatographie en phase gazeuse, Report DSM/CEA Saclay, CEA-R-5814, 1998.

Holben, B. N., T. F. Eck, I. Sluster, D. Tanré, J. P. Buis, A. Setzer, E. Vermote, J. A. Reagan, Y. J. Kaufman, T. Nakajima, F. Lavenu, I. Jankowiak, and Z. Smirnov, AERONET-A Federated instrument network and data archive for aerosol characterisation, Rem. Sens. Environ., 66, 1-16, 1998.

Jaecker-Voirol, A., M. Lipphardt, B. Martin, P. Quandalle, J. Sallès, B. Carissimo, E. Dupont, L. Musson-Genon, P. M. Riboud, B. Aumont, G. Bergametti, I. Bey, and G. Toupance, A $3 \mathrm{D}$ regional scale photochemical air quality model: application to a 3 day summertime episode over Paris, Rev. Inst. Fr. Pétrole, 53, 225-237, 1998.

Jin, S., and K. Demerjian, A photochemical box model for urban air quality study, Atmos. Environ., 27B, 371-387, 1993.

Lafore, J. P., J. Stein, N. Asencio, P. Bougeault, V. Ducrocq, J. Duron, C. Fischer, P. Hereil, P. Mascart, V. Masson, J. P. Pinty, J. L. Redelsperger, E. Richard, and J. Vila-Guerau de Arellano, The Meso-NH atmospheric simulation system. Part I: adiabatic formulation and control simulations, Ann. Geophysicae, 16, 90-109, 1998.

Lehning, M., H. Richner, G. L. Kok, and B. Neininger, Vertical exchange and regional budgets of air pollutants over densely populated areas, Atmos. Environ., 32, 1353-1363, 1998.

Lossec, B., Situation météorologique et pollution photo-oxydante sur la région Parisienne, La métrol. (in French), 8(8), 1994.

McElroy, J., and T. B. Smith, Creation and fate of ozone layers aloft in southern California, Atmos. Environ., 27A, 1917-1929, 1993.

Milford, J. B., D. Gao, and S. Sillman, Total reactive nitrogen $\left(\mathrm{NO}_{y}\right)$ as an indicator of the sensitivity of ozone to reductions in hydrocarbon and $\mathrm{NO}_{x}$ emissions, J. Geophys. Res., 99, 35333542, 1994.

Menut, L., C. Flamant, and J. Pelon, Evidence of synoptic scale influence on the atmospheric boundary layer dynamics and turbulent processes over the Paris area, Boundary Layer Meteorol., 93, 269-286, 1999.

Menut, L., R. Vautard, M. Beekmann, and C. Honoré, Sensitivity of photochemical pollution using the adjoint of a simplified 
chemistry-transport model, J. Geophys. Res., 105(D12), 15 37915 402, 2000.

Neftel, A., Examples of the importance of trace gas measurements in the Milan ozone plume, Analusis, 27, 325-327, 1999.

Peuch, V. H., M. Amodei, T. Barthet, M.-L. Cathala, B. Josse, M. Michou, and P. Simon, MOCAGE: Modèle de Chimie Atmosphérique à Grande Echelle, Atelier de Modélisation de l'Atmosphère' Conference, Toulouse, France, 1999.

Prévôt, A. S. H., J. Staehelin, G. L. Kok, R. D. Schillawski, B. Neininger, T. Staffelbach, A. Neftel, H. Wernli, and J. Dommen, The Milan photooxidant plume, J. Geophys. Res., 102, 23 375-23 388, 1997.

Rappenglueck, B., G. Jakobi, and P. Fabian, Comparison of PAN and $\mathrm{O}_{3}$ measurements during BERLIOZ, EGS Conference, Nice, France, 2000.

Sallès, J., J. Janischewski, A. Jaecker-Voirol, and B. Martin, Mobile source emissions inventory model: application to the Paris area, Atmos. Environ., 30, 1965-1975, 1996.

Sillman, S., The use of $\mathrm{NO}_{y}, \mathrm{H}_{2} \mathrm{O}_{2}$, and $\mathrm{HNO}_{3}$ as indicators for ozone- $\mathrm{NO}_{x}$-hydrocarbon sensitivity in urban locations, J. Geophys. Res., 100, 14 175-14 188, 1995.

Souffland, D., Développement et Validation d'un Modèle Tridimensionnel Non-Hydrostatique d'Écoulements Méso-Météorologiques en Terrain Complexe - Le Code Mercure, PhD Thesis, Institut National Polytechnique de Grenoble, 1985.
Touaty, M., Développement instrumental de la mesure en continu des hydrocarbures légers par chromatographie en phase gazeuse, PhD Thesis, University Paris 7, 1999.

Tulet, P., A. Maalej, V. Crassier, and R. Rosset, An episode of photooxidant plume pollution over the Paris region, Atmos. Environ., 33, 1651-1662, 1999.

Vautard, R., M. Beekmann, L. Menut, and M. Lattuati, Applications of adjoint modeling in urban air pollution. Proceedings of EUROTRAC Symposium'98, Eds. P. M. Borrell and P. Borrell, pp 502-508, WIT Press, Southampton, pp 1999.

Vautard, R., M. Beekmann, J. Roux, and D. Gombert, Validation of a deterministic forecasting system for the ozone concentrations over the Paris area, Atmospheric Environment, 2000, (in press).

Volz-Thomas, A., D. Mihelic, S. Konrad, H.-W. Ptz, N. Houben, U. Platt, and D. Perner, Local ozone production rates from photo stationary state of $\mathrm{O} 3 / \mathrm{NOx}$ and from peroxy radical measurements in the plume of Berlin during the BERLIOZ campaign, EGS Conference, Nice, France, 2000

Wesely, M. L., Parameterization of surface resistances to gaseous dry deposition in regional scale numerical models, Atmos. Environ., 23(6), 1293-1304, 1989.

Ziomas, I. C., The Mediterranean campaign of photochemical tracers-transport and chemical evolution (MEDCAPHOTTRACE): an outline, Atmos. Environ., 32, 2045-2054, 1998. 